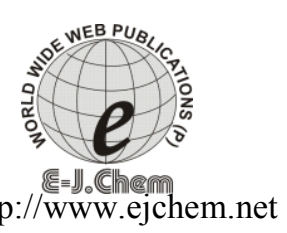

ISSN: 0973-4945; CODEN ECJHAO

E-Journal of Chemistry

2012, 9(3), 1053-1057

\title{
A Convenient and Efficient Protocol for the Synthesis of Adipic Acid Catalyzed by ACC/Silica Gel under Ultrasound Irradiation
}

\author{
ZHI-PING LIN \\ Department of Biology and Chemistry, Baoding University, Baoding 071000, P. R. China. \\ linzhiping888999@126.com
}

Received 10 November 2011; Accepted 15 January 2012

\begin{abstract}
Adipic acid was synthesized from cyclohexanol oxidized by ACC/silica gel in $89 \%$ yield within $3 \mathrm{~h}$ at $30^{\circ} \mathrm{C}$ under ultrasound irradiation.
\end{abstract}

Keywords: adipic acid; ACC/silica gel; synthesis; ultrasound irradiation.

\section{Introduction}

Adipic acid is a most important organic synthetic intermediate, and mainly used for synthetic fibers: nylon-66, other fields can also be widely used, for example polyurethane, synthetic resin, leather, polyester foam, plastic plasticizers, lubricants, food additives, adhesives, pesticides, dyes, spices, medicine ${ }^{1}$.

The adipic acid was synthesized usually throughout the oxidation of cyclohexene, cyclohexanol, cyclohexanone or a mixture of them or electro-oxidation of cyclohexanol ${ }^{2}$, with nitric acid, potassium permanganate, molecular oxygen, ozone, sodium hypochlorite ${ }^{3}$ as the oxidant. Much attention has been paid for its green synthesis process because of disadvantages in current technology. Hydrogen peroxide as a safe, gentle, clean, cheap and readily available oxidant, can replace traditional high-polluting oxidants in organic synthesis. But in these procedures, the expensive and complex catalysts for example, peroxotungstates and peroxomolybdates ${ }^{4}$, ZSM-5 supported metal ions (M/ZSM-5) and N-hydroxyphthalimide (NHPI) ${ }^{5}$, heteropoly complexes ${ }^{6}$, a carbon supported platinum catalyst ${ }^{7}$, Ti-AlSBA15 catalysts ${ }^{8}$, manganese diimine catalysts ${ }^{9}$, Co-substituted $\beta$-zeolites catalysts ${ }^{10}$, Ironphthalocyanine on zeolite $\mathrm{Y}^{11}$, tungstic acid/acidic organic additive ${ }^{12}$, phosphotungstic acid ${ }^{13}$ etc. have to be added in.

Ammonium chlorochromate (ACC) is a good oxidizing of secondary alcohols and has a wide range of applications in organic synthesis. It also has advantages of low price, easy preparation, stable, selective, with less, and easy separation of product.

Reagents supported on inorganic substrates have been received increasing attention in recent years as a means to develop convenient and environmentally friendly reagents. The 
concept of utilizing reagents adsorbed on inert inorganic supports has been reported and applied, especially to chromium compounds ${ }^{14}$. Ammonium chlorochromate (ACC) adsorbed on silica gel was another convenient oxidant recently reported. The use of silica gel as solid support has become very useful in synthetic organic chemistry because of the enhanced selectivity resulting from its large surface area. These reagents can oxidize various alcohols and have many advantages such as mild conditions, easy workup procedures, and good yields.

Ultrasound has increasingly been used in organic synthesis in the last three decades. A large number of organic reactions can be carried out in higher yields, shorter reaction time or milder conditions under ultrasound irradiation.

In this paper we wish to report an efficient and practical procedure for the synthesis of adipic acid with the oxidation of cyclohexanol by $\mathrm{ACC} /$ silica gel in $\mathrm{CH} 2 \mathrm{Cl} 2$ under ultrasound irradiation (Scheme 1).

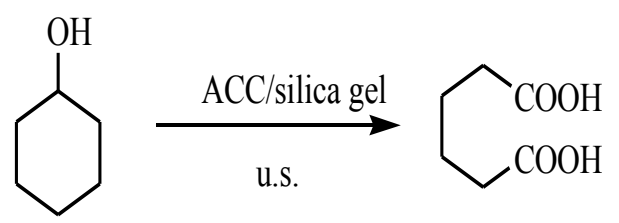

Scheme 1. Synthesis of adipic acid under ultrasound irradiation.

\section{Experimental}

Liquid substrates were distilled prior to use. Melting points were uncorrected. Sonication was performed in Shanghai BUG40-06 or BUG25-06 ultrasonic cleaner (with a frequency of 25 $\mathrm{kHz}, 40 \mathrm{kHz}, 59 \mathrm{kHz}$ and a nominal power $250 \mathrm{~W}$ ).

\section{Preparation of Ammonium Chlorochromate/Silica Gel ${ }^{15}$}

To a solution of chromium trioxide $(20 \mathrm{~g}, 0.2 \mathrm{~mol})$ in water $(50 \mathrm{~mL})$ is added ammonium chloride $(10.7 \mathrm{~g}, 0.2 \mathrm{~mol})$ within $15 \mathrm{~min}$ at $40^{\circ} \mathrm{C}$. The mixture is cooled until yellow-orange solid forms. Reheating to $40^{\circ} \mathrm{C}$, silica gel $(100 \mathrm{~g})$ is then added to the solution with stirring. After evaporation in a rotary evaporator the orange solid is dried for $2.5 \mathrm{~h}$ at $50^{\circ} \mathrm{C}$. The content of ACC in ACC/silica gel is about $15.3 \%$.

\section{Typical Procedure for the Preparation of Adipic Acid}

A 50-mL round flask was charged with cyclohexanol $(2 \mathrm{mmol})$, ACC/silica gel $(2.62 \mathrm{~g}$, including ACC $4 \mathrm{mmol})$, and $\mathrm{CH} 2 \mathrm{Cl} 2(8 \mathrm{~mL})$ in one portion. The reaction flask was located in the cleaner bath, where the surface of reactants was slightly lower than the level of the water. The mixture was irradiated $3 \mathrm{~h}$ (the reaction was monitored by TLC). The reaction products were isolated by filtration from the reaction mixture. Then the solvent was poured into crushed ice. The precipitate was separated by filtration, washed with water, and crystallized from water to obtain the adipic acid $256 \mathrm{mg}, 89 \%$, Mp: $152-153^{\circ} \mathrm{C}$.

\section{Results and Discussion}

In a preliminary experiment, the influence of the amount of ACC/silica gel on the yield was studied. It was found that a molar ratio of cyclohexanol: ACC/silica gel of 1:2 gave the best yield $(89 \%)$. By changing the molar ratio to $1: 1,1: 1.5,1: 2.25$, and 1:2.5 the yields decreased to $66 \%, 70 \%, 82 \%$ and $80 \%$ respectively (Table 1 ). The results showed that changing the molar 
ratio had a significant effect on the yield, and the optimum molar ratio of cyclohexanone:ACC/ silica gel was 1:2.

In the absence of ultrasound, on the oxidation of cyclohexanol to adipic acid by ACC/silica gel proceeded in only $40 \%$ yield within $3 \mathrm{~h}$ by stirring alone (Table 2 ). The oxidation gave adipic acid in $89 \%$ yield within $3 \mathrm{~h}$ under the ultrasonication of $25 \mathrm{kHz}$. While under $40 \mathrm{kHz}$ and 59 $\mathrm{kHz}$ ultrasound irradiation, the reaction was completed in $3 \mathrm{~h}$ with $73 \%$ and $70 \%$ yield respectively. It is apparent that the ultrasound can accelerate the oxidation, and lower frequency of ultrasound irradiation improves the yield. Therefore, the reaction was carried out with $25 \mathrm{kHz}$ ultrasound irradiation.

Table 1 The effects of the amount of ACC/silica gel on the oxidation of cyclohexanol to adipic acid under ultrasound irradiation*

\begin{tabular}{cccccc} 
Amount of ACC/silica gel, g & 1.31 & 1.97 & 2.62 & 2.95 & 3.28 \\
Yield, \% & 66 & 70 & 89 & 82 & 80 \\
\hline
\end{tabular}

*ultrasound frequency: $25 \mathrm{kHz}$; reaction time: $3 \mathrm{~h}$; reaction temperature: $30^{\circ} \mathrm{C}$.

Table 2 The effect of ultrasound frequency on the oxidation of cyclohexanol to adipic acid*.

\begin{tabular}{lllll}
\hline Ultrasound frequency, kHz & 25 & 40 & 59 & stiring \\
Yield, \% & 89 & 73 & 70 & 40 \\
\hline
\end{tabular}

*amount of ACC/silica gel: $2.62 \mathrm{~g}$; reaction time: $3 \mathrm{~h}$; reaction temperature: $30^{\circ} \mathrm{C}$.

As shown in Table 3, adipic acid gave a lower yield from the oxidation of cyclohexanol when the reaction time prolonged from $3.0 \mathrm{~h}$ to $4.0 \mathrm{~h}$. The reason may be that the prolonged reaction time would cause many other by-products within the reaction system.

Table 3 The effect of reaction time on the oxidation of cyclohexanol to adipic acid under ultrasound irradiation*.

\begin{tabular}{lllll}
\hline Reaction time , h & 2.5 & 3.0 & 3.5 & 4.0 \\
Yield, \% & 71 & 89 & 82 & 75 \\
\hline
\end{tabular}

*ultrasound frequency: $25 \mathrm{kHz}$; amount of ACC/silica gel: $2.62 \mathrm{~g}$; reaction temperature: $30^{\circ} \mathrm{C}$.

It was also found that reaction temperature has some effects on the oxidation of cyclohexanol to adipic acid. By changing the reaction temperature from $30^{\circ} \mathrm{C}$ to $25^{\circ} \mathrm{C}, 35^{\circ} \mathrm{C}$ and $40^{\circ} \mathrm{C}$ the yields decreased from $89 \%$ to $75 \%, 81 \%$ and $73 \%$ respectively (Table 4 ). This may be that the lower reaction temperature caused the lower reactivity, but the higher reaction temperature would cause other complex oxidation by-products and difficult workup procedures. Therefore, the reaction was carried out at $30^{\circ} \mathrm{C}$ under ultrasound irradiation. 
Table 4 The effect of reaction temperature on the oxidation of cyclohexanol to adipic acid under ultrasound irradiation*.

\begin{tabular}{lcccc}
\hline Reaction temperature, ${ }^{0} \mathrm{C}$ & 25 & 30 & 35 & 40 \\
Yield, \% & 75 & 89 & 81 & 73 \\
\hline
\end{tabular}

*ultrasound frequency: $25 \mathrm{kHz}$; amount of ACC/silica gel: $2.62 \mathrm{~g}$; reaction time: $3 \mathrm{~h}$.

Ammonium chlorochromate (ACC) adsorbed on silica gel have many advantages such as mild conditions, easy workup procedures, and good yields. The most important was that the oxidizing agent could recycle and the oxidizing power has no significant decrease after recycled two times (Table 5).

Table 5 The effect of recycled times of ACC/silica gel on the oxidation of cyclohexanol to adipic acid under ultrasound irradiation*.

\begin{tabular}{lcccc}
\hline Recycled times & 0 & 1 & 2 & 3 \\
Yield, \% & 89 & 79 & 74 & 60 \\
\hline
\end{tabular}

*ultrasound frequency: $25 \mathrm{kHz}$; amount of ACC/silica gel: $2.62 \mathrm{~g}$; reaction time: $3 \mathrm{~h}$.

Wang et al. 16 reported that the adipic acid was synthesized from cyclohexene oxidized by 30 $\% \mathrm{H} 2 \mathrm{O} 2$ in $55 \%$ yield at $90^{\circ} \mathrm{C}$ within $6 \mathrm{~h}$ which catalyzed by $\mathrm{H} 3 \mathrm{PW} 12 \mathrm{O} 40 / \mathrm{TiO} 2$. While in our system, the ACC/silica gel-oxidation reaction was given adipic acid in $89 \%$ yields under ultrasound irradiation within $3 \mathrm{~h}$ at $30^{\circ} \mathrm{C}$.

In summary, we have found an efficient and practical procedure for the synthesis of adipic acid via the oxidized by ACC/silica gel of cyclohexanol under ultrasound irradiation. The present procedure has many advantages such as short reaction time, mild conditions, easy operation procedures, and high yields.

\section{References}

1. Sato K, Aoki M and Noyori R, Science, 1998, 281, 1646.

2. Liang Z H, Cui Y Q and Sun H Y, Electrochemistry, 2008, 14, 40.

3. Rothenberg G and Sasson Y, Tetrahedron, 1996, 52, 13641.

4. Zhu W S, Li H M, He X Y, Zhang Q, Shu H M and Yan Y S, Catal. Commun., 2008, 9, 551 .

5. Yang D H, Liu M D, Zhao W J and Gao L, Catal. Commun., 2008, 9, 2407.

6. Ren S Y, Xie Z F, Cao L Q, Xie X P, Qin G F and Wang J D, Catal. Commun., 2009, 10, 464.

7. Béziat J C, Besson M and Gallezot P, Appli. Catal. A: General, 1996, 135, L7-L11.

8. Lapisardi G, Chiker F, Launay F, Nogier J P and Bonardet J L, Catal. Commun., 2004, 5, 277. 
9. Knops-Gerrits P P, Thibault-Starzyk F and Jacobs P A, Studies in Surface Science and Catalysis, 1994, 84, 1411.

10. Belkhir I, Germain A, Fajula F and Fache E, Studies in Surface Science and Catalysis, 1997, 110, 577.

11. Thibault-Starzyk F, Parton R F and Jacobs P A, Studies in Surface Science and Catalysis, 1994, 84, 1419.

12. Cao F B, Jiang H and Gong H, Chin. J. Org. Chem., 2005, 25, 96.

13. Meng Q Z, Dong Y H, Qin B Y and Zhou C S, Chem. World, 2005, (4), 226.

14. (a) Heravi M M, Hydar K T and Kiakojoori R, J. Chem. Res., Synop., 1998, 10, 656;

(b) Hajipour A R, Imanzadeh G and Mallakpour S E, Chem. Lett., 1999, 2, 99; (c) Lou J D and Xu Z N, Tetrahedron Lett., 2002, 43, 6149; (d) Lou J D and Xu Z N, Tetrahedron Lett., 2002, 43, 6095.

15. Zhang G S, Shi Q Z, Chen M and Cai K, Synth. Commun., 1997, 27, 953.

16. Wang Y H, Dong J H and Tang X H, Journal of Nanchang Institute of Aeronautical Technology (Natural Science Edition), 2006, 20, 28. 


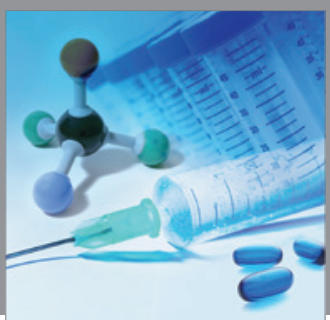

International Journal of

Medicinal Chemistry

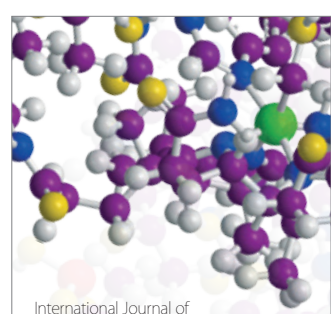

Carbohydrate Chemistry

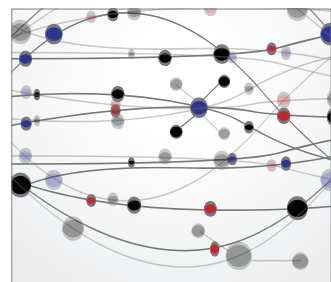

The Scientific World Journal
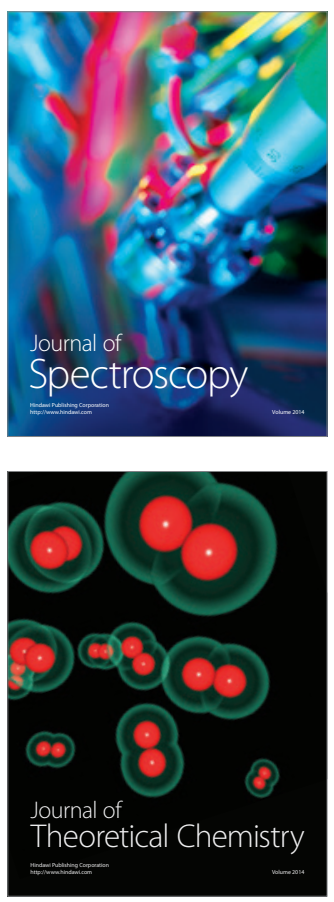
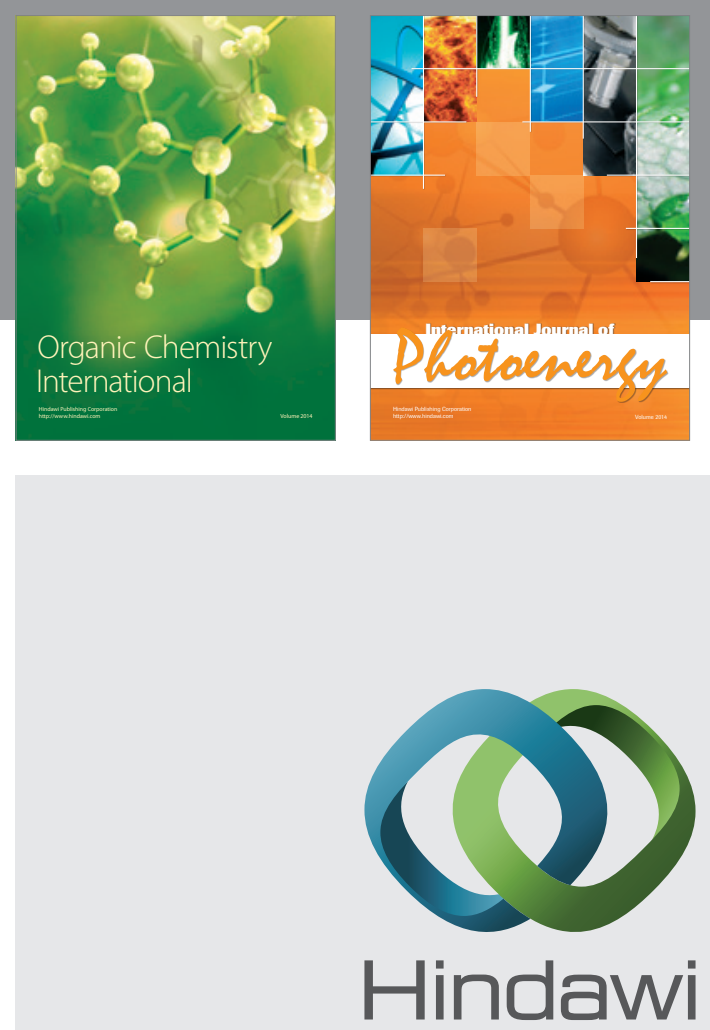

Submit your manuscripts at

http://www.hindawi.com
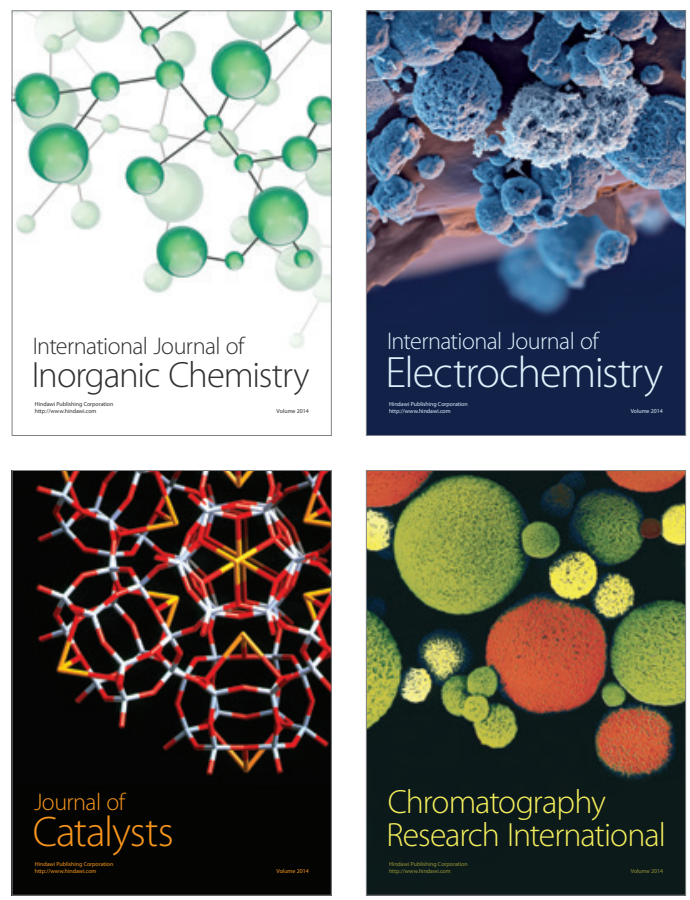
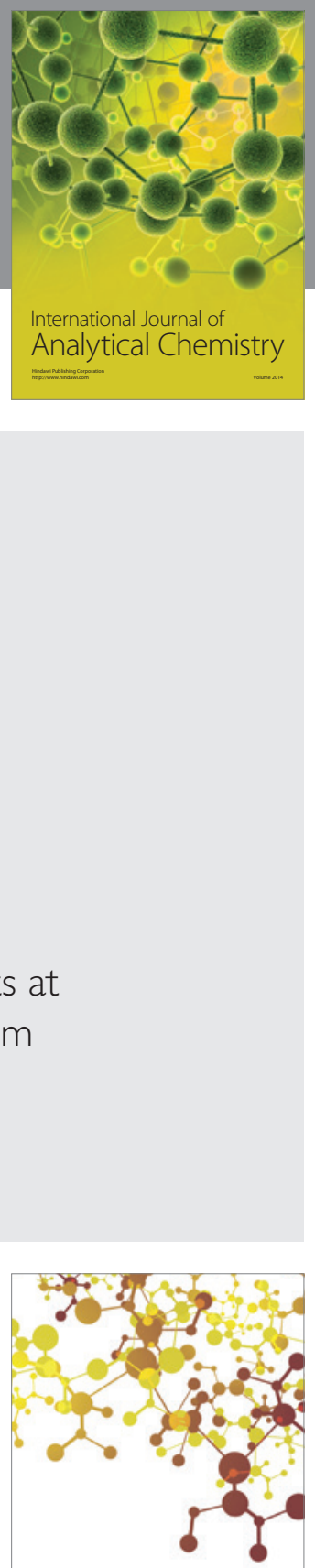

Journal of

Applied Chemistry
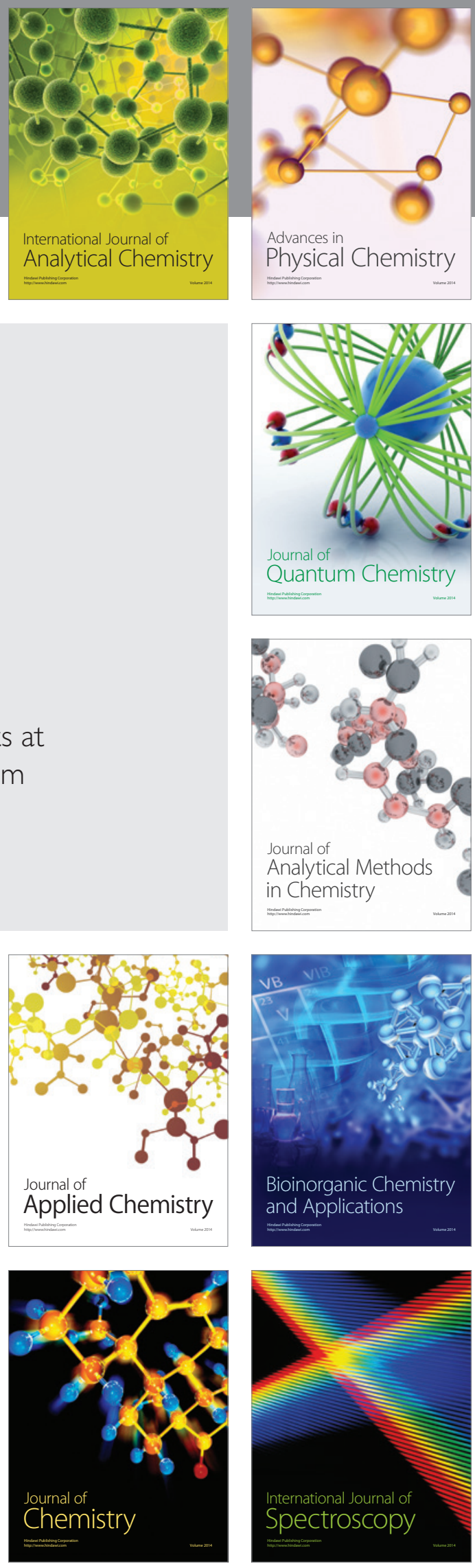